\title{
Salário-Maternidade e suas Alterações: um Direito Previdenciário, Trabalhista e Constitucional à Maternidade
}

\author{
Maternity Salary and its Changes: a Social Security, Labor and Constitutional Right to \\ Maternity
}

\author{
Bruna Roberta Mendes Pequito Yano
}

Anhanguera Uniderp, Pós-Graduação Lato Sensu em Direito Previdenciário: Teoria e Prática. MT, Brasil.

E-mail. brupequito@hotmail.com

\begin{abstract}
Resumo
Com o advento da Revolução Industrial, houve a ruptura com o modelo de sociedade feudal para a sociedade capitalista e a mulher ingressou no mercado de trabalho. Diante das injustiças sofridas pelas mulheres nas indústrias, surgiram as primeiras leis de proteção ao trabalho da mulher. Tem-se assim a proteção à maternidade, com a consequente concessão do salário-maternidade, assegurada pela Constituição Federal de 1988 e pelas leis previdenciárias vigentes. Dessa forma, o presente artigo tem como objetivo geral evidenciar a importância da viabilização e da divulgação da legislação previdenciária numa linguagem acessível e de fácil compreensão e assimilação pelo cidadão, traçando os contornos, características e hipóteses referentes ao salário-maternidade, e principalmente às respectivas alterações legislativas. Para alcançar o objetivo proposto, a pesquisa pode ser caracterizada como revisão bibliográfica, que envolve embasamento teórico, voltado à promoção e à efetivação de direitos constitucionais, trabalhistas e previdenciários materializados no salário-maternidade.
\end{abstract}

Palavras-chave: Salário-Maternidade. Proteção. Cidadania.

\begin{abstract}
With the advent of the Industrial Revolution, there was a break with the feudal society model for capitalist society and women entered the job market. Faced with the injustices suffered by women in the industries, the first laws to protect women's work appeared. Thus, there is maternity protection, with the consequent granting of maternity wages, ensured by the Federal Constitution of 1988 and by the current social security laws. Thus, this article has the general objective of highlighting the importance of enabling and disseminating social security legislation in an accessible and easily understood and assimilated language by the citizen, tracing the contours, characteristics and hypotheses regarding maternity wages, and especially the respective legislative changes. To achieve the proposed objective, the research can be characterized as a bibliographic review, which involves a theoretical basis, aimed at the promotion and enforcement of constitutional, labor and social security rights materialized in the maternity wage.
\end{abstract}

Keyword: Maternity Salary. Protection. Citizenship.

\section{Introdução}

O salário-maternidade constitui um benefício previdenciário com público-alvo definido e que visa a tutela à maternidade, à gestante, à infância e à família, previstas na Constituição, bem como dar eficácia a normas de proteção integral à criança, previstas do Estatuto da Criança e do Adolescente.

O tema se justifica tendo em vista as constantes alterações verificadas na legislação que rege o Direito Previdenciário como um todo, desde a promulgação da Constituição Federal de 1988 até os dias atuais, tendo como foco o salário-maternidade. Assim, em razão da chamada "inflação legislativa" verificada no cenário brasileiro, faz-se de extrema importância o conhecimento e a divulgação dos requisitos do salário-maternidade e as alterações legais daí decorrentes, pois dessa forma, estar-se-á protegendo o direito da mãe e da criança enquanto sujeitos de direito e, de forma implícita, o direito à informação, constitucionalmente garantido.

O salário-maternidade é um benefício previdenciário com inúmeras particularidades e de grande relevância social que tem sofrido constantes alterações legislativas. Por essa razão, grande parte da população, público-alvo do referido benefício, pelos mais variados motivos, fica alheia a informações e alterações legislativas básicas, deixando muitas vezes de exercer um direito que lhes caberia.

Nesse contexto, o presente estudo tem como objetivo geral evidenciar a importância da viabilização e da divulgação da legislação previdenciária numa linguagem acessível e de fácil compreensão e assimilação pelo cidadão, traçando os contornos, características e hipóteses referentes ao saláriomaternidade, e principalmente às respectivas alterações legislativas. Pois assim, estar-se-á garantindo o direito à maternidade e, reflexamente o direito à cidadania através da informação.

Em termos específicos, objetiva-se apresentar as características e os requisitos do salário-maternidade de forma ampla, visando informar, disseminar o conhecimento dos direitos tutelados constitucionalmente e despertar uma visão crítica sobre o tema; elencar as alterações legislativas sobre o salário-maternidade; esclarecer questões pontuais que visem 
evitar a disseminação de conceitos distorcidos; e incentivar e fomentar a educação previdenciária e a discussão sobre os deveres e os direitos previdenciários, especificamente sobre o salário-maternidade, pois uma população informada, torna-se mais consciente de seus direitos e deveres, podendo exigir, questionar, enfim, exercer a cidadania de forma efetiva.

\section{Desenvolvimento}

\subsection{Metodologia}

A Metodologia utilizada no presente estudo vem a ser a revisão bibliográfica, que envolve embasamento teórico, voltado à promoção e à efetivação de direitos constitucionais, trabalhistas e previdenciários materializados no salário maternidade.

Segundo Lakatos e Marconi (2007), entende-se por pesquisa bibliográfica toda bibliografia que já se tornou pública, abrangendo desde livros, boletins, jornais, revistas, monografias, teses, entre outros, até meios de comunicações orais. Os autores complementam que tal método de pesquisa não é mera repetição do que já foi dito ou escrito a respeito de determinado assunto, mas propicia o exame de um tema sob novo enfoque ou abordagem, chegando a novas conclusões.

Assim, com a utilização de uma seleção de artigos científicos e livros que abordam assuntos referentes ao benefício previdenciário em questão, visa-se proporcionar a síntese de conhecimento e a incorporação da aplicabilidade de resultados de estudos significativos na prática. Através do processo socioeducativo, o segurado da Previdência Social, aliando informação e reflexão consegue adquirir mais autonomia no que se refere a suas garantias e obrigações, amplia sua visão de mundo, podendo exercer seus direitos e cumprir seus deveres de forma mais participativa, efetiva e crítica e assim, influenciar e conduzir outros que se encontrem na mesma situação.

No presente estudo faz-se necessário, como base principal e determinante, a análise da Constituição Federal de 1988 base do Estado Democrático de Direito e do Estatuto da Criança e do Adolescente - ECA, cujos dispositivos fortalecem e estimulam ações significativas para os envolvidos, colocandoos como sujeitos de direitos e de obrigações.

\subsection{Seguridade Social}

Iniciando a explanação com uma breve contextualização histórica, a ideia de Proteção Social teve início, de acordo Castro e Lazzari (2012), na necessidade de serem estabelecidos métodos de proteção contra os diversos riscos a que o ser humano está sujeito, sendo a partir do final do século XIX que a questão começou a adquirir importância e ser tratada pelas legislações governamentais. Considerando a conceituação da expressão Proteção Social, tem-se:

Proteção social, portanto, é um conjunto de medidas de caráter social destinadas a atender certas necessidades individuais; mais especificamente, às necessidades individuais que, não atendidas, repercutem sobre os demais indivíduos e, em última análise, sobre a sociedade (CASTRO; LAZZARI, 2012, p.21).

De acordo com Castro e Lazzari (2012), desde o início da vida em comunidade, o homem se preocupou em garantir seu sustento e de sua família diante das incertezas naturais, como as situações de risco decorrentes de fenômenos da natureza, e também aquelas advindas de riscos sociais, como morte, doença ou perda de renda. Assim, passou-se a percebeu ser necessário auxílio externo para amparar os indivíduos das situações de risco.

Santos (2011) analisa que a evolução histórica da Proteção Social ocorreu com base nos ideais de caridade, que eram geridos, especialmente pela Igreja. Como não havia influência alguma do Estado, a pessoa que se encontrava em situação de necessidade era amparada pelos demais membros da comunidade através da caridade.

Com o desenvolvimento da sociedade industrial, a atenção do Estado passa a voltar-se aos problemas sociais crescentes. Bragança (2012) contextualiza que o descontentamento das classes trabalhadoras em consequência dos efeitos colaterais do desenvolvimento humano, principalmente após a Revolução Industrial, fez emergir os seguros sociais, mas ainda não levaram a proteção social. Somente na segunda metade do século XX, sobretudo em função da destruição da Segunda Guerra Mundial, tem-se um Estado preocupado com o bem-estar social, surgindo a ideia de seguridade social.

Considerando a realidade do Brasil, a definição da expressão Seguridade Social pode ser encontrada no artigo194 da Constituição Federal de 1988, abordando que:

Art. 194. A seguridade social compreende um conjunto integrado de ações de iniciativa dos poderes públicos e da sociedade, destinadas a assegurar os direitos relativos à saúde, à previdência e à assistência social.

Parágrafo único. Compete ao poder público, nos termos da lei, organizar a seguridade social, com base nos seguintes objetivos:

I - universalidade da cobertura e do atendimento;

II - uniformidade e equivalência dos benefícios e serviços às populações urbanas e rurais;

III - seletividade e distributividade na prestação dos benefícios e serviços;

IV - irredutibilidade do valor dos benefícios;

V - eqüidade na forma de participação no custeio;

VI - diversidade da base de financiamento;

VII - caráter democrático e descentralizado da gestão administrativa, com a participação da comunidade, em especial de trabalhadores, empresários e aposentados (BRASIL, 1988).

Em relação ao conceito, Menezes (2016) leciona que a seguridade social pode ser definida como a proteção que a sociedade oferece aos seus membros mediante contra as privações econômicas e sociais que procedem do desaparecimento ou em forte redução de sua subsistência, como consequência de enfermidade, maternidade, acidente de trabalho ou enfermidade profissional, desemprego, invalidez, velhice e também a proteção em forma de assistência médica e ajuda às famílias com filhos. 
Bragança (2012) expõe que a Seguridade Social foi subdividida em Saúde, Previdência e Assistência Social com o objetivo de abranger três formas de proteção social. Em relação as finalidades da Seguridade Social, Balera e Mussi (2014) contextualizam que a seguridade social tem como propósito fundamental proporcionar para os indivíduos e suas famílias a tranquilidade de saber que o nível e a qualidade de suas vidas não serão significativamente diminuídos, até onde for possível evitá-lo, por nenhuma circunstância econômica ou social, sendo assegurado condições mínimas de sobrevivência digna.

\subsection{Proteção da mulher e da maternidade}

Historicamente, Barroso (2010) relata que o marco inicial adotado para a proteção à maternidade consiste no período em que o trabalho se tornou efetivamente remunerado pelo dono do meio de produção e, simultaneamente, quando o trabalhador passou a realizar o trabalho de forma contínua e subordinada. Assim, segundo o autor, a Revolução Industrial representou uma ruptura com o modelo de sociedade feudal para a sociedade capitalista.

Nesse período, de inserção da mulher no mercado de trabalho capitalista, não houve proteção. Nascimento (2007) relata que durante a Revolução Industrial no século XIX, o trabalho feminino nas empresas foi aproveitado em larga escala, isso porque havia aceitação em receber salários inferiores aos dos homens, tornando-se vantajoso ao empregador. O Estado não interferia nas relações trabalhistas, deixando a mulher vulnerável a todo tipo de exploração.

No Brasil, Martins (2006) relata que a Constituição de 1934 trouxe diversas conquistas para as mulheres, como o direito ao voto, no âmbito eleitoral e a proibição de distinção salarial sexista, na área trabalhista. Quanto à proteção da maternidade, institui o repouso antes e após o parto e previu serviços de amparo à maternidade.

Entretanto, Martins (2006) salienta que como o pagamento do período de afastamento da gestante ficou como responsabilidade do empregador, a contratação das mulheres passou a diminuir, pois não era vantajoso ao empregador. Para solucionar esse problema social, foi necessário que a responsabilidade pelo pagamento do salário-maternidade fosse repassada para Previdência Social. Nesse interim, a Organização Internacional do Trabalho - OIT, na convenção $\mathrm{n}^{\circ} 103$, que passou a vigorar no Brasil em 18 de junho de 1966, através do Decreto $\mathrm{n}^{\circ} 58.820$, apresentou de forma expressa que "Em hipótese alguma, deve o empregador ser tido como pessoalmente responsável pelo custo das prestações devidas às mulheres que ele emprega.

Continuando a explanação, a Constituição Federal de 1967 garantiu o direito ao descanso remunerado para as gestantes, sem comprometer o emprego e salário, trazendo também a proteção da Previdência Social à maternidade.

Castro e Lazzari (2012) abordam que a Lei $n^{\circ} 6.136$ de 1974 desonerou o empregador do pagamento do salário da empregada gestante no período de afastamento do serviço, que era de doze semanas na época. Neste momento é que, no Brasil, se torna encargo da Previdência Social o pagamento referente ao benefício, com a empresa adiantando o salário e depois sendo reembolsada pelo INSS.

Com a Constituição Federal de 1988, passa-se a ter a seguinte redação:

Art. 201. A previdência social será organizada sob a forma de regime geral, de caráter contributivo e de filiação obrigatória, observados critérios que preservem o equilíbrio financeiro e atuarial, e atenderá, nos termos da lei, a:

II -proteção à maternidade, especialmente à gestante.

Complementarmente, no artigo $7^{\circ}$ inciso XVIII, ampliase o prazo de duração da licença-maternidade para 120 dias, elencando a proteção à maternidade como direito fundamental (BRASIL, 1988).

De forma mais ampla, a proteção à maternidade foi consolidado pela Constituição Federal de 1988, em seu artigo $6^{\circ}$, como um direito social que visa garantir proteção à gestante e, principalmente, a criança.

Art. $6^{\circ}$. São direitos sociais a educação, a saúde, a alimentação, o trabalho, a moradia, o transporte, o lazer, a segurança, a previdência social, a proteção à maternidade e à infância, a assistência aos desamparados, na forma desta Constituição (BRASIL, 1988).

Verifica-se que no texto constitucional não há muitos dispositivos que se destinam ao instituto da maternidade, mas a sua inserção entre o rol dos direitos sociais confere uma importância elevada em relação a outros direitos e garantias.

\subsubsection{Salário-Maternidade}

Para que a proteção a maternidade aconteça de maneira eficaz, Bragança (2012) relata que o benefício devido aos segurados quando ocorre as hipóteses de parto, aborto não criminoso ou adoção é o salário-maternidade.

A Constituição Federal de 1988, por trazer os princípios da proteção integral dos direitos da criança e do adolescente, com absoluta prioridade é de extrema importância para este trabalho. Determina em seu artigo 227, segundo o qual:

Art. 227. É dever da família, da sociedade e do Estado assegurar à criança e ao adolescente, com absoluta prioridade, o direito à vida, à saúde, à alimentação, à educação, ao lazer, à profissionalização, à cultura, à dignidade, ao respeito, à liberdade e à convivência familiar e comunitária, além de coloca-los a salvo de toda forma de negligência, discriminação, exploração, violência, crueldade e opressão (BRASIL, 1988).

No artigo $5^{\circ}$ do referido diploma legal, é feito menção ao direito à informação enquanto dever do Estado, o qual se faz imprescindível para o exercício da cidadania, ressalvado os casos de sigilo legalmente previstos.

Art. $5^{\circ}$. Todos são iguais perante a lei, sem distinção de qualquer natureza, garantindo-se aos brasileiros e aos estrangeiros residentes no País a inviolabilidade do direito à vida, à liberdade, à igualdade, à segurança e à propriedade, nos termos seguintes: 


\section{$[\ldots]$}

XXIII - todos têm direito a receber dos órgãos públicos informações de seu interesse particular, ou de interesse coletivo ou geral, que serão prestadas no prazo da lei, sob pena de responsabilidade, ressalvadas aquelas cujo sigilo seja imprescindível à segurança da sociedade e do Estado (BRASIL, 1988).

A proteção à maternidade e à infância são elencadas pela Constituição Federal de 1988 como um direito social no artigo $6^{\circ}$ e também é mencionada no artigo 201, conforme segue:

Art. $6^{\circ}$. São direitos sociais a educação, a saúde, a alimentação, o trabalho, a moradia, o transporte, o lazer, a segurança, a previdência social, a proteção à maternidade e à infância, a assistência aos desamparados, na forma desta Constituição.

Art. 201. A previdência social será organizada sob a forma de regime geral, de caráter contributivo e de filiação obrigatória, observados critérios que preservem o equilíbrio financeiro e atuarial, e atenderá, nos termos da lei, a:

$[\ldots]$

II - proteção à maternidade, especialmente à gestante. (BRASIL, 1988)

O referido artigo 227 coloca a criança como foco central de todas as preocupações constitucionais, determinando que seus direitos e interesses devem ser observado antes de qualquer outro interesse ou preocupação, uma vez que é necessário defender o direito constitucional de que crianças e adolescentes têm de estar salvas de toda forma de violência, crueldade e opressão para que tenham uma vida digna, enquanto pessoas em situação peculiar de desenvolvimento e enquanto seres humanos. Por este motivo, o texto constitucional deve constituir a base do presente trabalho. Até porque o objetivo deste se confunde com a finalidade e os objetivos da Constituição Federal do Brasil de 1988.

Ortega (2018) menciona que a Constituição Federal de 1988 garante às mulheres que tiverem filho, uma licença remunerada para que possam durante um tempo se dedicar exclusivamente à criança, ou seja, a licença-maternidade, e está previsto no artigo $7^{\circ}$, XVIII. A autora aborda que não existe fundamento constitucional para tratar de forma desigual a mãe gestante e da mãe adotante, não devendo haver, razão para diferenciar o adotado mais velho do mais novo, referindo-se ao prazo que havia antes da Lei ${ }^{\circ} 12.873 / 2013$, para recebimento do salário-maternidade de acordo com a idade da criança adotada.

Nesse mesmo entendimento e ampliando a abordagem, Ibrahim (2014) leciona que o salário-maternidade é devido à segurada empregada, trabalhadora avulsa, empregada doméstica, contribuinte individual, facultativa ou segurada especial, em decorrência do parto (inclusive no caso de mãe substitutiva) e do aborto não criminoso. Salientando-se também que a Lei $n^{\circ}$. 10.421/02 ampliou esse rol, abrangendo os casos de adoção de crianças ou da obtenção da guarda judicial para fins de adoção.

Quanto à natureza jurídica do salário-maternidade, é de extrema importância ressaltar que este vem a ser um benefício previdenciário pago pela previdência e não pelo empregador. Nesse sentido, Carrion (2006) assevera ser direito previdenciário, que não obriga ao pagamento pelo empregador, mas apenas a permitir a ausência da gestante durante todo o período, como licença remunerada pelo INSS, sendo o chamado salário-maternidade.

Martins (2006) define o benefício como hipótese de interrupção do contrato de trabalho, sendo o tempo de serviço contado normalmente durante o afastamento. Assim, o saláriomaternidade é um pagamento feito pelo INSS à empregada durante os 120 dias da licença-maternidade. O tempo de serviço é contado normalmente durante o afastamento, tratando-se, assim, de hipótese de interrupção do contrato de trabalho. Terminando o afastamento, as obrigações mútuas contratuais continuam como se não tivesse havido interrupção.

No mesmo enfoque, Maranhão (1993, p.160) coloca que:

O salário-maternidade é um beneficio previdenciário, sendo devido pela Previdência Social, enquanto subsistir o vínculo empregatício (art. 71, da Lei no 8.213/91). O empregador paga o salário e é reembolsado pela Previdência Social (art. 72). Para a empregada doméstica o salário-maternidade será pago diretamente pela Previdência Social em valor correspondente ao do seu último salário de contribuição (art. 73).

Assim, o salário-maternidade é um benefício previdenciário, sendo, portanto, efetuado pela previdência e não pelo empregador, com por vezes equivocadamente se faz supor. Pois empregador realiza o pagamento do saláriomaternidade à previdência e é reembolsado pelo valor pago à previdência, com deduções nos seus débitos. Fato este que deve ficar bem claro, a fim de evitar informações distorcidas e até mesmo a discriminação da mão-de-obra feminina.

Sobre o benefício pago à trabalhadora avulsa, Martins (2006) esclarece que o salário-maternidade da trabalhadora avulsa consistirá em uma remuneração mensal igual a sua remuneração integral e será pago pelo INSS.

Martins (2006) aborda que o salário da segurada durante período do salário-maternidade não pode sofrer qualquer abatimento.

Entende o STF que o salário-maternidade não está sujeito ao limite de R\$1.200,00, devendo o INSS pagar o benefício integralmente, independentemente do valor do salário da trabalhadora gestante. Os ministros do STF afirmam que a limitação contraria a Constituição, em razão de que gestante tem garantido o direito à licença-maternidade, sem prejuízo do emprego e do salário, com duração de 120 dias (art. $7^{\circ}$, XVIII) (MARTINS, 2006, p. 581).

Como elucida o Superior Tribunal Federal, o salário da gestante no período de licença não pode sofrer alteração, tendo por base a garantia constitucional da licença-maternidade à gestante sem prejuízo do emprego e do salário.

Considerando a legislação específica que trata do tema, a Lei $n^{\circ} 8212 / 91$ que dispõe sobre a organização da Seguridade Social e institui Plano de Custeio, a Lei no 8213/91 que aborda sobre os Planos de Benefícios da Previdência Social e o Decreto $\mathrm{n}^{\circ} 3.048 / 99$ foram a base do presente estudo, pois traçam e determinam os contornos dos benefícios previdenciários e, 
mais especificamente ao salário-maternidade

A Lei $n^{\circ} 8.213 / 91$ em seus artigos 25, 26 e 39 determina carência do salário-maternidade, a qual se subordina à categoria em que a segurada está alistada. Para as contribuintes particulares, específicos e facultativas são determinadas 10 contribuições mensais para a permissão. As seguras empregadas, até mesmo a doméstica, e as trabalhadoras independentes estão escusadas da carência.

O artigo 101 do decreto 3.048/99 assim dispõe sobre a forma de cálculo do salário-maternidade: $\mathrm{O}$ saláriomaternidade consistirá: I- Em valor correspondente ao seu último salário de contribuição para a assegurada doméstica; II- Em um doze avos da soma dos doze último salários de contribuição, apurados em período não superior a quinze, para as asseguradas contribuinte individual, facultativa e para as que mantenham a qualidade de segurada na forma do artigo 13 (BRASIL, 1999).

Dessa maneira, no caso de segurada empregada, o salário-maternidade será pago diretamente pela empresa, efetivando-se a compensação na ocasião do recolhimento das contribuições incidentes da folha de pagamento e demais rendimentos pagos ou creditados. Para as demais seguradas inclusive as trabalhadoras independentes e funcionárias do microempreendedor e no caso de adoção, será pago pela Previdência Social.

A Instrução Normativa $n^{\circ} 77$ INSS/PRESS de 21/01/2015 traça os principais requisitos do salário-maternidade, contendo inclusive as alterações que se seguiram, conforme segue:

Art. 71. Ao segurado ou segurada da Previdência Social que adotar ou obtiver guarda judicial para fins de adoção de criança é devido salário-maternidade pelo período de 120 (cento e vinte) dias (BRASIL, 2015).

Por se tratar de um direito trabalhista, far-se-á necessária análise de dispositivos da Consolidação das Leis Trabalhistas (CLT), tais como o artigo 392, que dispõe que a empregada gestante tem direito à licença-maternidade de 120 (cento e vinte) dias, sem prejuízo do emprego e do salário.

De acordo com Martins (2006), são elencadas várias alterações do salário-maternidade, dentre elas:

a) a Lei n. ${ }^{\circ}$ 10.710/03 que restabeleceu o pagamento, pela empresa, do salário-maternidade devido à segurada empregada gestante;

b) a Lei 11.770/2008 que criou o Programa Empresa Cidadã, destinado à prorrogação da licença-maternidade mediante concessão de incentivo fiscal, e altera a Lei no 8.212, de 24 de julho de 1991 - a ampliação do conceito de família, fazendo jus ao recebimento do salário-maternidade, qualquer pessoa na condição de mãe ou pai, biológico ou não;

c) o salário-maternidade ao cônjuge sobrevivente (artigo $71 B$ da Lei 8.213/91 e art. 342 da IN 77/2015);

d) a alteração do limite da idade da criança adotada e do período do recebimento do benefício em questão conforme a Lei ${ }^{\circ} 12.873 / 2013$, segundo a qual o saláriomaternidade foi devido somente à segurada adotante, pelo prazo de 120 (cento e vinte) dias, quando da adoção de criança de até doze anos de idade incompletos; e) a possibilidade da concessão do salário-maternidade quando há a adoção de criança ou guarda para fins de adoção pelo adotante do sexo masculino e por casais homoafetivos (Lei no 12.873/13);

f) o direito ao salário-maternidade do empregado do microempreendedor individual $\left(\S 3^{\circ}\right.$ do artigo 72 da Lei 8.213/91);

g) os reflexos da Lei Complementar $n^{\circ}$ 150/2015 que instituiu o Simples Doméstico e suas implicações no benefício sob análise.

Outra importante alteração verificada foi a edição do Memorando Circular Conjunto $n^{\circ} 44$ /DIRBEN/PFE/INSS, que prevê que o INSS deve conceder e pagar diretamente o salário-maternidade, ainda que a gestante tenha sido demitida "sem justa causa", considerando a decisão judicial proferida no Agravo de Instrumento de $\mathrm{n}^{\circ}$ 5055114-88.2017.4.04.0000/ $\mathrm{PR}$, que estendeu a eficácia territorial da decisão na Ação Civil Pública $\mathrm{n}^{\mathrm{o}}$ 504131527.2017.4.04.7000/PR para todo o território nacional.

Conforme a decisão emitida pela $17^{\mathrm{a}}$ Vara Federal de Curitiba, o INSS deve conceder o benefício de saláriomaternidade às gestantes desempregadas no curso da gravidez, preenchidos os demais requisitos ao benefício, pagando os diretamente, ficando afastado o entendimento de que o pagamento do benefício seria de responsabilidade da empresa nos casos de gestantes demitidas "sem justa causa", de que trata o art. 97 do Regulamento da Previdência SocialRPS, aprovado pelo Decreto n ${ }^{\circ} 3.048 / 99$.

Nesse sentido, conforme dispõe o memorando:

O benefício de salário-maternidade já é devido às seguradas em período de manutenção de qualidade de segurado, cabendo, em cumprimento aos demais comandos da determinação judicial, a concessão às seguradas em manutenção da qualidade de segurado demitidas sem justa causa durante o período de gestação, restando afastada a aplicação da orientação contida no inciso IV, art. 352, da Instrução Normativa ${ }^{\circ}$ 77/INSS/ PRES, de 21 janeiro de 2015.

Evidencia-se que a edição do referido Memorando significou grande avanço tanto na esfera dos diretos previdenciários quanto trabalhistas.

Em 18 de janeiro de 2019 foi editada a Medida Provisória $n^{\circ} 871$ que trouxe dentre outras mudanças, a decadência do direito ao salário-maternidade, a qual se opera se o benefício não for requerido em até 180 da ocorrência do parto ou adoção, exceto na ocorrência de motivo de força maior ou caso fortuito nos termos do art. 71-D, vindo a substituir a prescrição que se verificava quando a criança completava 05 (cinco) anos de idade, nos termos do artigo 71 da Lei no 8.213/91.e artigo 354, IN 77/2015 INSS/PRES.

Outra mudança referente ao salário-maternidade trazida pela referida Medida Provisória consta em seu art. 27-A, conforme segue:

Art. 27-A. Na hipótese de perda da qualidade de segurado, para fins da concessão dos benefícios de auxílio-doença, de aposentadoria por invalidez, de salário-maternidade e de auxílio-reclusão, o segurado deverá contar, a partir da data da nova filiação à Previdência Social, com os períodos integrais 
de carência previstos nos incisos I, III e IV do caput do art. 25 .

Assim, conforme o artigo acima, havendo a perda da qualidade de segurado, as contribuições anteriores a essa data só serão computadas para efeito de carência para fins de salário-maternidade, depois que a segurada contar, a partir da nova filiação à Previdência Social, com novas 10 contribuições mensais e não mais com $1 / 3$ (um terço) do número de contribuições exigidas para o cumprimento da carência definida para o referido benefício.

Verifica-se, portanto, ser imprescindível o acompanhamento das alterações legislativas principalmente quando o que está em jogo são direitos constitucionalmente tutelados, tais como o direito ao salário-maternidade, dada a importância de sua função social que visa a proteção à mãe e à criança.

O papel da mulher na sociedade tem sido revolucionado nas últimas décadas e, de acordo com Paulon (2000), o saláriomaternidade vem cumprindo seu papel social no referente a proteção do trabalho das mulheres no período da gravidez, tanto no amparo financeiro como na garantia de emprego.

Complementando, a maternidade possui e desempenha função social, conforme descrito no artigo $6 .^{\circ}$ da Constituição Federal de 1988. Bossa (1998) analisa que as medidas protetivas legisladas buscam garantir à mulher a sua função biológica de ser mãe, evitando que ocorram determinados riscos que poderiam vir a ameaçar sua saúde e o desenvolvimento da gravidez e da criança. A autora relata que a finalidade do salário-maternidade consiste garantir à mulher a proteção necessária durante a gestação, no período de amamentação e parto, com o objetivo de dar suprimento para a trabalhadora gestante que se afasta de suas atividades laborativas durante o período que a lei estabelece como essencial para seu restabelecimento físico e psicológico.

Costa (2010) contextualiza que o Brasil é um país que tem grande população pobre, que sofre os efeitos do neoliberalismo, constatando-se que a atuação do Poder Judiciário e a Constituição de 1988 contribuíram para o desenvolvimento dos direitos previdenciários. Nesse interim, a licença-maternidade na área trabalhista juntamente com o salário-maternidade na esfera previdenciária, foram conquistas da sociedade brasileira que contribui para a dignidade à pessoa humana, propiciando condições sociais para o recém-nascido como o afeto, amamentação.

Assim, Costa (2010) apregoa que a finalidade social do salário-maternidade consiste em possibilitar o descanso para a mulher trabalhadora e garantir o contato da mãe com a criança nos primeiros meses de vida, garantindo simultaneamente a proteção da mulher, da criança e a cobertura dos encargos familiares.

\section{Conclusão}

Através do processo informativo, expositivo e socioeducativo, espera-se com o estudo que a segurada, público-alvo do salário-maternidade, aliando informação e reflexão, consiga adquirir mais autonomia, ampliando sua visão de mundo, podendo exercer seus direitos e cumprir seus deveres de forma mais participativa, efetiva e consciente e assim, possa influenciar e conduzir outros que se encontrem na mesma situação.

Sob pena de decadência do direito ao benefício em questão o qual deve ser requerido em até 180 dias da ocorrência do parto ou da adoção, exceto na ocorrência de motivo de força maior ou caso fortuito, alteração esta trazida pela edição da Medida Provisória $n^{\circ} 871$ em 18 de janeiro de 2019 no art. 71-D, e sob pena de se abrir mão de um direito constitucionalmente protegido qual seja, o da informação, sem muitas vezes saber da existência desse direito.

Pretende-se assim, ressaltar que a comunidade acadêmica e jurídica e os profissionais da área, têm o dever de disseminar informações referentes ao salário-maternidade, bem como aos demais benefícios previdenciários e suas respectivas alterações. Tendo por base a Constituição Federal a qual coloca o direito à informação como direito fundamental, bem como, a Lei n. ${ }^{\circ}$ 12.527/2011, constitui importante veículo normativo que instrumentaliza o cidadão de meios de acesso à informação, seja no âmbito da proteção dos direitos individuais ou na tutela dos direitos coletivos transindividuais, inclusive a previsão de sanção à recusa ou demora no fornecimento da informação ou do local onde possa ser encontrada.

\section{Referências}

BALERA, W.; MUSSI, C.M. Direito Previdenciário. São Paulo: Método, 2014.

BARROSO, L.R Judicialização, ativismo judicial e legitimidade democrática. Rev. Direito do Estado, n. 13, 2010.

BOSSA, S. Direito do trabalho da mulher: no contexto social brasileiro e medidas antidiscriminatórias. São Paulo: Oliveira Mendes, 1998.

BRAGANÇA, K.H. Manual de Direito Previdenciário. Rio de Janeiro: Forense, 2012.

BRASIL. Decreto n. 5452, de $1^{\circ}$ de maio de 1943. Aprova a Consolidação das Leis do Trabalho. Disponível em: http://www. planalto.gov.br/ccivil_03/decretolei/Del5452.htm. Acesso em: 19 out. 2018.

BRASIL. Constituição da República Federativa do Brasil: promulgada em 5 de outubro de 1988. Disponível em: http://www. planalto.gov.br/ccivil_03/constituicao/constituicaocompilado. htm. Acesso em: 15 out. 2018.

BRASIL. Lei n. 8212, de 24 de julho de 1991. Dispõe sobre a organização da Seguridade Social, institui Plano de Custeio. Disponível em: http://www.planalto.gov.br/ccivil_03/LEIS/ L8212cons.htm. Acesso em: 16 out. 2018.

BRASIL. Lei n. 8213, de 24.07.1991. Dispõe sobre os Planos de Benefícios da Previdência Social. Disponível em: http://www. planalto.gov.br/ccivil_03/Leis/L8213cons.htm. Acesso em: 16 out. 2018 .

BRASIL. Decreto 3.048, de 06 de maio de 1999. Aprova o Regulamento da Previdência Social, e dá outras providências. 
Disponível em: http://www.planalto.gov.br/ccivil 03/decreto/ D3048.htm. Acesso em: 16 outubro 2018

BRASIL. Lei n. 9876, de 26 de novembro de 1999. Dispõe sobre a contribuição previdenciária do contribuinte individual, o cálculo do benefício, altera dispositivos das Leis nos 8.212 e 8.213, ambas de 24 de julho de 1991, e dá outras providências. Disponível em: http://www.planalto.gov.br/ccivil_03/LEIS/ L9876.htm. Acesso em: 17 out. 2018.

BRASIL. Lei n. 10.421, de 15 de abril de 2002. Estende à mãe adotiva o direito à licença-maternidade e ao salário-maternidade, alterando a Consolidação das Leis do Trabalho, aprovada pelo Decreto-Lei no 5.452, de 1 o de maio de 1943, e a Lei no 8.213, de 24 de julho de 1991. Disponível em: http://www.planalto.gov.br/ ccivil_03/leis/2002/110421.htm. Acesso em: 14 out. 2018.

BRASIL. Lei n. 10.710, de 05 de agosto de 2003. Altera a Lei no 8.213 , de 24 de julho de 1991, para restabelecer o pagamento, pela empresa, do salário-maternidade devido à segurada empregada gestante. Disponível em:

http://www.planalto.gov.br/ccivil_03/LEIS/2003/L10.710.htm. Acesso em: 21 out. 2018.

BRASIL. Lei n.11.457, de 16 de março de 2007. Dispõe sobre a Administração Tributária Federal; altera as Leis nos 10.593, de 6 de dezembro de 2002, 10.683, de 28 de maio de 2003, 8.212, de 24 de julho de 1991, 10.910 de 15 de julho de 2004, o Decreto Lei no 5.452, de 1 de maio de 1943, e o Decreto no 70.235 , de 6 de março de 1972; revoga dispositivos das Leis nos 8.212, de 24 de julho de 1991, 10.593, de 6 de dezembro de 2002, 10.910, de 15 de julho de 2004, 11.098, de 13 de janeiro de2005, e 9.317, de 5 de dezembro de 1996; e dá outras providências. Disponível em: http://www.planalto.gov.br/ccivil_03/_Ato20072010/2007/Lei/ L11457.htm. Acesso em: 15 out. $2 \overline{0} 18$.

BRASIL. Lei n.11.770, de 09 de setembro de 2008. Cria o Programa Empresa Cidadã, destinado à prorrogação da licençamaternidade mediante concessão de incentivo fiscal, e altera a Lei no 8.212, de 24 de julho de 1991. Disponível em: http://www. planalto.gov.br/ccivil_03/ato2007-2010/2008/lei/111770.htm. Acesso em: 27 out. $20 \overline{1} 8$.

BRASIL. Lei n. 12.527/2011, de 18 de novembro de 2011. Regula o acesso a informações previsto no inciso XXXIII do art. 5o, no inciso II do $\S 30$ do art. 37 e no $\S 20$ do art. 216 da Constituição Federal; altera a Lei no 8.112, de 11 de dezembro de 1990; revoga a Lei no 11.111, de 5 de maio de 2005, e dispositivos da Lei no 8.159 , de 8 de janeiro de 1991; e dá outras providências. Disponível em: http://www.planalto.gov.br/ccivil 03/ ato20112014/2011/lei/112527.htm. Acesso em: 20 out. 2018.

BRASIL. Lei n. 12.873, de 24 de outubro de 2013. Altera as Leis nos 8.212, de 24 de julho de 1991, e 8.213, de 24 de julho de 1991, o Decreto-Lei no 5.452, de 1 o de maio de 1942 - Consolidação das Leis do Trabalho, as Leis nos 11.491, de 20 de junho de 2007, e 12.512, de 14 de outubro de 2011. Disponível em: http://www. planalto.gov.br/ccivil_03/Ato2011-2014/2013/Lei/L12873.htm. Acesso em: 01 nov. 2018 .

BRASIL. Instrução Normativa INSS/PRESS n. 77, de 21 de janeiro de 2015. Estabelece rotinas para agilizar e uniformizar o reconhecimento de direitos dos segurados e beneficiários da Previdência Social, com observância dos princípios estabelecidos no art. 37 da Constituição Federal de 1988. Disponível em: http:// sislex.previdencia.gov.br/paginas/38/inss-pres/2015/77.htm. Acesso em: 30 outubro 2018.

BRASIL. Lei Complementar n. 150, de 01 de junho de 2015. Dispõe sobre o contrato de trabalho doméstico; altera as Leis no 8.212, de 24 de julho de 1991, no 8.213, de 24 de julho de 1991, e no 11.196 , de 21 de novembro de 2005; revoga o inciso I do art. 3o da Lei no 8.009, de 29 de março de 1990, o art. 36 da Lei no 8.213, de 24 de julho de 1991, a Lei no 5.859, de 11 de dezembro de 1972, e o inciso VII do art. 12 da Lei no 9.250, de 26 de dezembro 1995; e dá outras providências. Disponível em: http://www.planalto.gov.br/ccivil 03/leis/LCP/Lcp150.htm. Acesso em: 10 out. 2018.

BRASIL. Memorando-Circular Conjunto $\mathrm{n}^{\circ} 44$ /DIRBEN/PFE/ INSS, de 30 de novembro de 2017. Disponível em: https:// previdenciarista.com/noticias/inss-pagarasalario-maternidadesegurada-demitida-sem-justa-causa/. Acesso em: 3 nov. 2018.

BRASIL. Medida Provisória $\mathrm{n}^{\circ} 871$ de 18 de janeiro de 2019. Disponível em: http:/www.planalto.gov.br/ccivil 03/ Ato20192022/2019/Mpv/mpv871.htm. Acesso em: 2 fev. 2019

CARRION, V. Comentários à consolidação das leis do trabalho. São Paulo: Saraiva. 2006.

CASTRO, C.A.P; LAZZARI, J.B. Direito Previdenciário Acadêmico. Florianópolis: Conceito, 2012.

COSTA, J.R.C. Previdência: os direitos sociais previdenciários no cenário neoliberal. Curitiba: Juruá, 2010.

IBRAHIM, F.Z. Curso de Direito Previdenciário. Rio de Janeiro: Impetus, 2014.

LAKATOS, E.M.; MARCONI, M.A. Fundamentos de metodologia científica. São Paulo: Atlas, 2007.

MARANHÃO, D. Direito do Trabalho. São Paulo. Getúlio Vargas, 1993.

MARTINS, S.P. Direito do trabalho. São Paulo: Atlas, 2006.

MARTINS, S.P. Direito da seguridade social. São Paulo: Atlas, 2006.

MENEZES, A. Direito Previdenciário. Salvador: Juspodivm, 2016.

NASCIMENTO, A. M. Iniciação ao direito do trabalho. São Paulo: LTR, 2007.

ORTEGA, F.T. Prazo da licença-adotante deve ser obrigatoriamente o mesmo da licença-maternidade. Disponível em: https://draflaviaortega.jusbrasil.com.br/noticias/322890354/ prazo-da-licencaadotante-deve-ser-obrigatoriamente-o-mesmoda-licenca-maternidade. Acesso em: 20 out. 2018.

PAULON, R.M. Salário-maternidade: um benefício em gestação. Rev. Previdência Soc., v.24, n.239, 2000.

SANTOS, M.F. Direito previdenciário esquematizado. São Paulo: Saraiva, 2011. 